\title{
Empty Sella [Presenting as Hypopituitarism] and Platybasia Secondary to Essential Fatty Acids Deprived Diet. Proof of Basic Concept Study by Retrospective Analysis
}

\author{
Elizabeth Jeyavardhini Samuel, Darmalingam, S. Natarajan, Ramalingam, \\ Celestine Raj Manohar, Sundararajan Veerakesari, Uma Kanthan, Chetty Kanagaraj \\ Karpagam Faculty of Medical Sciences and Research, Coimbatore, India \\ Email: elizabethjsamuel@gmail.com
}

How to cite this paper: Samuel, E.J., Darmalingam, Natarajan, S., Ramalingam, Manohar, C.R., Veerakesari, S., Kanthan, U. and Kanagaraj, C. (2019) Empty Sella [Presenting as Hypopituitarism] and Platybasia Secondary to Essential Fatty Acids Deprived Diet. Proof of Basic Concept Study by Retrospective Analysis. Open Journal of Preventive Medicine, 9, 95-104. https://doi.org/10.4236/oipm.2019.98009

Received: June 24, 2019

Accepted: August 27, 2019

Published: August 30, 2019

Copyright $\odot 2019$ by author(s) and Scientific Research Publishing Inc. This work is licensed under the Creative Commons Attribution International License (CC BY 4.0).

http://creativecommons.org/licenses/by/4.0/

\begin{abstract}
Background: Universal concern is an increased prevalence of morbidity, mortality; with improper comprehension, the globe has implemented, non evidence-based medical practice, without therapeutic indication, therapeutic protocols, policies-contraception, abortion, annihilating human race by therapy, destroying germ cells with consecutive systemic inflammatory response syndrome, associated with decreased androgen oestrogen resulting in metabolic syndrome, increased neoplasms-due to lacuna of this comprehension-cholesterol was blamed, resulting in essential fatty acids deprived diet, promoting sunflower seed oil, refined oil, lipid-lowering agents prescription like water, for the past $>40$ years; the tragedy of this false concept of refined oil, essential fatty acids deprived diet, [against God-ordained marvelous cell metabolism, from cholesterol] resulting in degenerative diseases, defaulted genomic repertoire, as cause and effect phenomenon in the two following morbid, fatal case presentations; contraception, abortion is the culprit and not cholesterol which is the basic life moiety of cell membrane, cell metabolism governing steroid hormones-androgen oestrogen derived from cholesterol. Case 1: 76-year-old male, vegetarian, presented with lethargy, hypotension, unexplained hyponatremia, on fludrocortisone for 2 years. MRI detected empty sella; hence hypopituitarism with cortisol deficiency, resulting in hyponatremia was considered and with hydrocortisone replacement, patient improved. Low levels of LDL, HDL, suggested chronic [ $>40$ years] deprivation of diet containing essential fatty acids had resulted in degenerative-empty sella status with hypopituitarism. Case 2: 17-year-old girl presented with headache, vomiting, feeble pulse; 6 months prior platybasia had
\end{abstract}


been diagnosed and she had undergone corrective neurosurgery, to widen bilaterally, narrowed, base of skull foramina, to prevent compression on the exiting neurovascular bundles; urgent CT scan of brain confirmed significant narrowing of foramen magnum, compressing brainstem; she expired within 30 minutes secondary to brainstem edema. Low levels of HDL, LDL confirmed, long term [ 16 years] deprivation of essential fatty acids intake, leading to decreased steroid hormone synthesis-including oestrogen-the surveilling hormone for cell metabolism, including skull base, having resulted in progressive Platybasia, compressing brainstem. Conclusion: Though both patients belonged to affluent society it was the sincere adherence to the false detrimental concept of essential fatty acids deprived diet, which was the cause and effect phenomenon of degenerative empty sella syndrome, ineffectual cell-bone metabolism presenting as platybasia.

\section{Keywords}

Empty Sella Syndrome, Platybasia, Hyponatremia

\section{Introduction}

Global statistics reflect, manifold increasing prevalence of morbidity, mortality, which induces global concern; metabolic syndrome, systemic inflammatory response syndrome, defaulted genomic repertoire, poor healing capacity in the cells, i.e. impaired new cell formation; increase in degenerative diseases, neoplastic diseases, autoimmune diseases, infectious diseases are on the rise, by wanton unaware germ cells destruction by non evidence based medical practice, i.e. without therapeutic indication, therapeutic protocols, therapeutic policies, implementation of contraception, abortion, resulting in germ cells destruction, associated with agonisingly reduced androgen, oestrogen, followed by deranged cell metabolism, autoimmune diseases, neoplasms.

Unaware of this cholesterol was blamed, because of contraception, abortion, cholesterol was getting dammed and not getting utilised for cell membrane synthesis, steroid hormone synthesis, bile acid synthesis; but a false concept of essential fatty acids deprived diet, refined oil, sunflower seed oil [meant for parrots-human cells lack the LDL receptors for sunflower seed oil] resulting in impaired cell metabolism, metabolic defect, degenerative and neoplastic diseases to increase 6 fold, $60 \%$ [1].

\section{Case-1}

76-year-old male presented to emergency services, with history of drowsiness, muscle weakness, lethargy, apathy, anorexia, giddiness, of 2 years duration; hyponatremia had been detected to be present repeatedly, for the past $\sim 2$ years; he had visited a few hospitals prior and he was being treated with fludrocortisone for the same, with no improvement. He had no children-he was infertile. With 
caution, concern, ardently he was consuming essential fatty acids deprived diet, including sunflower refined oil, for many years.

On examination he was thin built, with lean muscle mass, skin was wrinkled, fine, and striking pallor was present; he was drowsy, poorly responding to questions; axillary pubic hair was sparse, minimal gynecomastia and pedal oedema were seen; his blood pressure was $80 / 60 \mathrm{mmHg}$; cardiovascular, respiratory, abdominal, central nervous system examinations were otherwise within normal limits.

The elderly male had hypotension, he was drowsy, and hypo natremia was persistent-the etiology had not been elucidated and the treatment with fludrocortisone had not been reverted the hyponatremic status or other clinical manifestations for the past two years, he was morbid and was monitored in Intensive care unit.

Investigations revealed, mild anaemia of Hemoglobin-9.4 gm\%, poor anabolic status suggested by HDL-28 $\mathrm{mg} / \mathrm{dl}$, poor intake of essential fatty acids containing diet suggested by LDL-68 mg/dl, secondary hypothyroid status suggested by triiodothyronine T3-49 ng/dl [adults reference range: 60 - 151 $\mathrm{ng} / \mathrm{dl}$ ], thyroxine T4-3.9 ng/dl [adults reference range: $5.1-14.1 \mathrm{ng} / \mathrm{dl}$ ], TSH $3.9 \mathrm{ng} / \mathrm{dl}$ [reference range: $0.27-4.2 \mathrm{ng} / \mathrm{dl}$ ], cortisol levels $-4.5 \mathrm{mcg} / \mathrm{dl}$.

His MRI brain showed cerebral atrophy, the description of MRI denoted, Empty Sella.

Empty sella-the description seen in MRI, enabled consideration of Empty Sella Syndrome, resulting in hypopituitarism and secondary adrenal insufficiency, [unlike in primary adrenal insufficiency, the hyper pigmentation by compensatory rise in ACTH was lacking and his skin was pale in appearance] as clinical diagnosis, was confirmed by serum cortisol levels.

He received treatment with hydrocortisone 15 mg AM - 5 mg PM; levothyroxin replacement was also initiated with $50 \mathrm{mcg} 6 \mathrm{AM}$, to be titrated as guided by every 45 days, serum T4, T3 estimation.

Patient improved dramatically, as cause and effect phenomenon, his hypotension, hyponatremia, lethargy, drowsiness, anorexia improved.

He was advised essential fatty acids rich diet comprising of nuts and seeds preparations, virgin olive oil or virgin coconut oil for cooking, [virgin olive oil, coconut oil contain all the growth supporting life factors, to support the life and growth of olive tree, coconut tree from the corresponding seeds, nuts transferred to the respective oil] frying, to consume milk with its cream, dairy products, to enable synthesis of new cell membranes, steroid hormones, to improve anabolism, depicted by better HDL, LDL levels in follow up, to address the degenerative pathology, rising 6 fold, $60 \%$, with refined oil [oil removed of its fatty acids, sunflower seed oil] in every tissue including pituitary, sella turcica, Pia Arachnoid membranes.

\section{Discussion}

Empty Sella Syndrome is a non tumorous enlargement of the Sella, results from 
a defect in the dural diaphragm, can occur without obvious cause, or follow surgical excision of a pituitary adenoma or pituitary apoplexy.

Arachnoid [2] over the defective dural diaphragm of sella will bulge through holes and then sella enlarges gradually, apparently as a result of the pressure and pulsations of the cerebrospinal fluid acting on the walls of sella turcica; in the process, pituitary gland becomes flattened, sometimes to an extreme degree, but the functions of the gland are usually unimpaired; downward herniation of the optic chiasma occurs occasionally and may cause visual disturbances, simulating those of a pituitary adenoma.

Adrenal insufficiency presents variably, so a high [3] degree of suspicion is required in patients with unexplained fatigue, hyponatremia, or hypotension; random plasma cortisol is usually low in patients with adrenal insufficiency, but it may be within normal range, yet inappropriately low for a seriously ill patient; random measurement of plasma cortisol, cannot therefore be used to refute or confirm the diagnosis, unless the value is high $>17 \mathrm{mcg} / \mathrm{dl}$.

Hypopituitarism describes combined deficiency of any of the anterior pituitary hormones; clinical presentation is variable and depends on the underlying lesion and the pattern of resulting hormone deficiency; with progressive lesions of the pituitary, there's a characteristic sequence of loss of pituitary hormone secretion; growth hormone secretion is often the earliest to be lost in adults, this produces [4] lethargy, muscle weakness, increased fat mass [these features are not obvious in isolation].

Next gonadotropin [FSH, LH] secretion becomes impaired, with loss of libido in the male and oligomenorrhoea, amenorrhoea in the female; later in the male, there may be gynecomastia, decreased axillary and pubic hair, may become sparse or absent and the skin becomes fine and wrinkled; chronic anaemia may also be seen.

Next is ACTH deficiency, resulting in symptoms of cortisol insufficiency; in contrary to primary adrenal insufficiency, angiotensin II-dependent, zona glomerulosa function is not lost and hence aldosterone secretion maintains normal plasma potassium.

However there may be postural hypotension and dilution hyponatremia for three reasons:

1) Failure of vasoconstriction in the absence of cortisol, results in pooling of blood in the legs on standing;

2) Antidiuretic hormone release is enhanced by hypotension and cortisol deficiency;

3) Cortisol is required for normal excretion of water by the kidneys.

In contrast to the pigmentation of Addison's disease, a striking degree of pallor is usually present, principally because of lack of stimulation of melanocytes by beta lipotrophic hormone [Beta LPH a fragment of the ACTH precursor peptide] in the skin.

Finally TSH secretion is lost with consequent secondary hypothyroidism; this contributes further to apathy and cold intolerance; in contrast to primary hypo- 
thyroidism, myxoedema is rare, presumably because thyroid retains some autonomous function.

Onset of all the above symptoms is notoriously insidious.

Acutely unwell patients, it's important to treat cortisol [4] deficiency; hydrocortisone to be given as $15 \mathrm{mg} 6 \mathrm{AM}-5 \mathrm{mg} 6 \mathrm{PM}$; mineralocorticoid replacement is not required; sodium depletion is not important component to treat.

Thyroxin 100 - 150 mcgm once daily may be required; unlike in primary hypothyroidism, measuring TSH is not helpful in adjusting replacement dose, because patients with hypopituitarism often secrete glycoproteins, measured in TSH assays, but are not bioactive; aim to maintain T4 in upper part of reference range.

It is dangerous to give thyroid replacement, without correcting adrenal insufficiency, without giving glucocorticoid therapy; this will precipitate adrenal crisis.

This elderly male was sincerely consuming sunflower seed oil, refined oil, avoiding fried preparations, consuming fat free milk; hence essential fatty acids deprived diet will result in reduced cholesterol synthesis, leading to low LDL, IDL, with resultant reduced steroid hormone synthesis, cell membrane [1] synthesis, and bile acid synthesis, leading to reduced HDL formation reflecting on increased associated degenerative changes in all tissue, including Dura, Pia Arachnoid, leading to Empty Sella with consecutive changes and hypopituitarism.

\section{Case-2}

17-years-old girl presented to emergency services, early morning- 5 AM, with headache, vomiting, giddiness, vertigo, imbalance in gait, requiring help to enable her walk into emergency services; all the above symptoms started 1 - 2 hours prior to admission; she had vomited 3 - 4 episodes, that morning.

6 months prior she had undergone neurosurgical intervention, to enable widening of foramina of base of skull, bilaterally. She was diagnosed to have platybasia, about 1 year ago.

On examination, she was short-statured, fair complexion, good looking young girl being helped to walk into emergency services, with people's support; she was sweating profusely, peripheries were cold, $\mathrm{BP}-80 / 60 \mathrm{mmHg}$, radial artery pulse was feeble, thready, rapid about $96 /$ minute, she was vomiting in the emergency services also.

She was drowsy, poorly responding to questions, pupils were small, with sluggish reaction; cardiovascular system examination and respiratory system examination showed no abnormalities; there was no obvious skeletal abnormalities, scapula or shoulder; probably her neck appeared short or appropriate for her short stature of $\sim 156 \mathrm{~cm}$ height, both her parents also were short, without any obvious illness, aged forty to fifty years of age, from middle class economy.

Urgent CT scan was done, considering the past history of platybasia, with surgeries performed to widen bilateral, base of skull, narrowed neurovascular 
foramina by platybasia pathology, to assess for probable foramen magnum narrowing, resulting in constriction of brain stem. CT scan images confirmed significant foramen magnum narrowing, with brain stem oedema, but no haemorrhage.

Random blood sugar estimation measured $68 \mathrm{mg} / \mathrm{dl}$, previous HDL-21 $\mathrm{mg} / \mathrm{dl}$, [denoting poor anabolic status], LDL-86 mg/dl, [denoting poor oral intake of essential fatty acids containing diet, confirmed as sunflower refined oil—fed with concern, avoiding fried preparations from childhood].

Her vital parameters continued to deteriorate inspite of parenteral steroids to reduce brainstem edema, parenteral fluids, inotropic support and she expired within 30 minutes following admission.

\section{Discussion}

Bony skeleton of the head is termed skull, consisting of 22 bones, excluding ear ossicles; excluding mandible, all the bones [5] of the skull are joined together by sutures, are immobile and form the cranium.

An upper dome shaped part which covers the cranial cavity, containing brain is called cranial vault/calvarial brain box: it is attached to the skull base below, the calvaria, along with skull base is called cranial skeleton/cranium.

Cranium provides case for protection of the brain and its coverings [meninges], provides cavities for accommodation of organs like brainstem, and provides openings for passage of nerves, blood vessels, spinal cord.

[6] Platybasia means broad base. It is the result of congenital maldevelopment of the sphenoid and/or occipital bones. Martins basilar angle, [angle formed by clival line and a line drawn along the floor of anterior cranial fossae], if this angle is more than 152 degrees, platybasis [7] exists. The above Figure 1 depicts this abnormality.

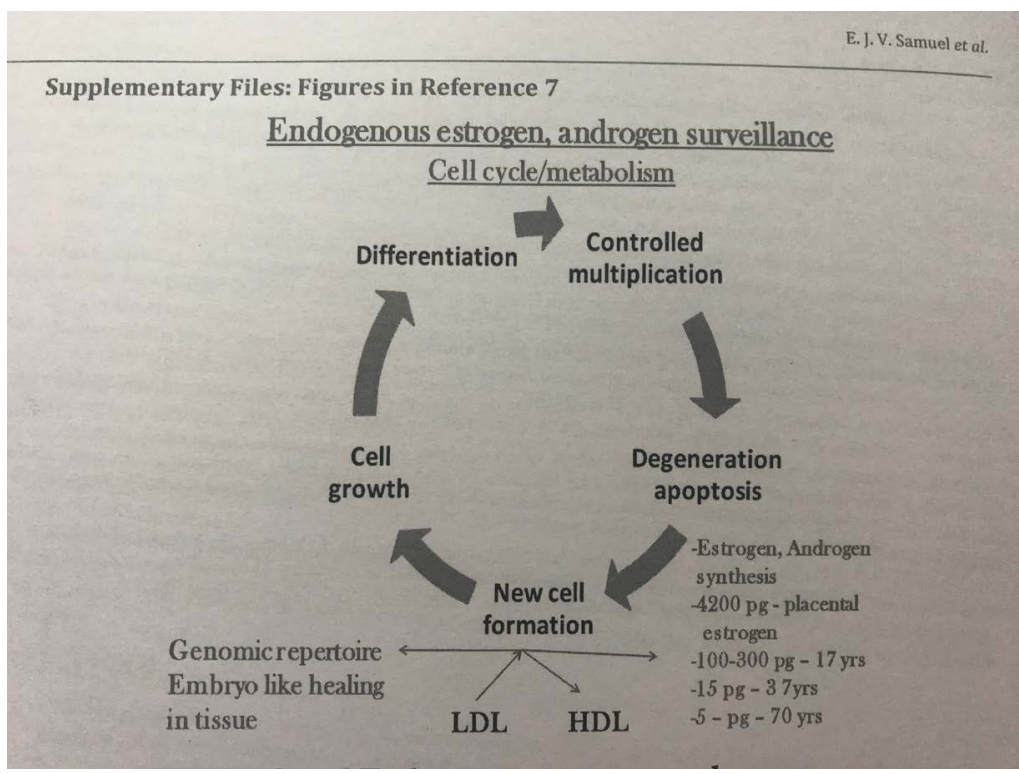

Figure 1. Endogenous estrogen, and rogen surveillance-Cell cycle/metabolism. 
Platybasia is associated with occipitalisation of $\mathrm{C} 1$ and Klippel-Feil syndrome. Basilar invagination is defined as, upward displacement of vertebral column and elements, into the foramen magnum, with platybasia.

Skull bones reveal areas of cotton wool or osteoporosis circumscripta, thickening of diploid areas and sclerosis of a portion, or all of one or more skull bones for unclear reason.

Symmetric or asymmetric enlargement of the parietal or frontal bones leads to frontal bossing, cranial expansion may narrow cranial foramen, and cause neurologic complications, including cochlear nerve damage, from temporal bone involvement, cranial nerve palsies and softening of the base of the skull [platybasia], with the risk of brainstem [8] compression.

This young girl was fed on refined oil, sunflower seed oil, with love and concern from childhood, was avoiding fried preparations, hence her LDL was low; her steroid hormone synthesis, [governing new cell formation-cell metabolism] new cell membrane synthesis were reduced, resulting in poor anabolism of all tissues, [reflected by her very low HDL] including bone metabolism, as a consequence platybasia, which progressed as even her diet was not corrected to include virgin coconut oil, or virgin olive oil, oil preparations, for lack of awareness, that cholesterol is the basic life factor of cell membrane and it's the animal fat-triglycerides deleterious.

\section{Analysis}

The precursor of all steroids is cholesterol; some of the cholesterol is synthesised from acetate but most of it is taken up from [9] LDL in the circulation.

Cholesterol is the precursor of the steroid hormones, bile acids and is an essential constituent of cell [10] membranes. It is found only in animals. Related sterols occur in plants, but plant sterols are poorly absorbed from the gastrointestinal tract. Most of the dietary cholesterol is contained in egg yolks.

Animals fed a fat free diet, fail to grow, develop skin, kidney lesions and become infertile; adding linolenic, linoleic and arachidonic acids to the diet cures all deficiency symptoms; these three acids are polyunsaturated and are called essential fatty acids.

Vitamin E is widely distributed in food supply in nuts, cereal grains, soya bean oil, small amounts in fruits and vegetables; vitamin E acts as chain breaking antioxidant and is an efficient peroxyl radical scavenger that protects [11] LDL, polyunsaturated fats in membranes from oxidation.

Reference [12] HDL $\rightarrow$ LDL $\rightarrow$ HDL $\rightarrow$ LDL [metabolic process].

Essential fatty acids [diet] $\rightarrow$ Cholesterol $\rightarrow$ LDL, IDL [circulation] $\rightarrow$ cholesteryl esters donated $\rightarrow$ cell membrane [1] synthesis, steroid hormone synthesis, bile acid synthesis $\rightarrow$ HDL [reflects on the robust health in cells, new cell formation, healing capacity in the cells].

Cell death $\rightarrow$ cholesteryl esters of cell membranes $\rightarrow$ adsorb onto HDL by, Lecithin cholesteryl acyl transferase [LCAT] $\rightarrow$ LDL.

Figure 1 as seen above depicts cell metabolism governed by androgen, estro- 
gen derived from cholesterol, synthesised from essential fatty acids.

Cell Metabolism $\rightarrow$ [under oestrogen, androgen surveillance].

Cell growth $\rightarrow$ differentiation $\rightarrow$ controlled multiplication $\rightarrow$ degeneration $\rightarrow$ Programmed cell death [apoptosis] $\rightarrow$ new cell formation [13].

1) Defective cell metabolism - [impaired androgen, oestrogen surveillance] $\rightarrow$ impaired cell growth $\rightarrow$ differentiation, $\rightarrow$ controlled multiplication $\rightarrow$ apoptosis $\rightarrow$ Impaired new cell formation $\rightarrow$ fibrosis, degeneration, gliosis.

2) Defective cell metabolism-[impaired androgen, oestrogen surveillance] $\rightarrow$ impaired cell growth $\rightarrow$ no differentiation, $\rightarrow$ uncontrolled multiplication $\rightarrow$ neoplasms.

Cell metabolism denotes every cell, tissue, organ is made a new, every 48 hours, [eg. heart, lungs, neurons, dura, Pia arachnoid, bone, skull base] by catabolism [cell death, degeneration] and anabolism [new cell formation], requiring cholesterol, synthesised from essential fatty acids present in the diet-to form new cell membranes incorporating cytoplasm to become every new cell, being governed by androgen, oestrogen surveillance, also synthesised from cholesterol.

Hence when cholesterol synthesis gets impaired by recommended essential fatty acids deprived diet [sun flower seed oil with 6 times [14] less vitamin E than ground nut oil, refined oil removed of its life factors associated fatty acids, prohibiting nuts and seeds preparations from wherein seedlings sprout] consumption, degeneration sets in every cell as a consequence of impaired metabolism, including dura of sella turcica as in case 1, and impaired metabolism of bone, skull base resulting in platybasia as in case 2

\section{Conclusions}

Elderly male presenting with unsolved hyponatremia, resolved as secondary cortisol deficiency, following degeneration in dura of sella turcica leading to empty sella syndrome resulting in hypopituitarism, was consuming essential fatty acids deprived diet [sunflower seed refined oil, milk without cream, avoiding fried preparations], by a misconcept to avoid virgin olive oil, virgin coconut oil, [with its life factors \{vitamin E, phyto-oestrogen, growth trophic factors\} containing fatty acids-for cooking.

As seen in Table 1, both the patients' HDL/LDL values were drastically low,

Table 1. Correlation between HDL, LDL levels \& degenerative pathology, deranged cell metabolism-metabolic syndrome.

\begin{tabular}{|c|c|c|c|c|c|c|}
\hline Problems & Age & HDL/LDL & Socioeconomic & EFA deprived diet & Morbidity & Treatment outcome \\
\hline $\begin{array}{c}\text { Empty } \\
\text { sella/hypopituitarism }\end{array}$ & 76 years & $28 / 68 \mathrm{mg} / \mathrm{dl}$ & $\begin{array}{l}\text { Rich, educated, } \\
\text { affluent society, } \\
\text { high caste } \\
\text { brahmin }\end{array}$ & $\begin{array}{l}\text { Essential fatty acids } \\
\text { deprived diet was } \\
\text { strictly adhered to } \\
\text { for }>40 \text { years }\end{array}$ & $\begin{array}{l}\text { hypotension, lethargy, } \\
\text { drowsiness, } \\
\text { hyponatremia, infertility }\end{array}$ & $\begin{array}{l}\text { Improved dramatically with } \\
\text { hydrocortisone treatment, } \\
\text { Essential fatty acids rich diet. }\end{array}$ \\
\hline Platybasia & 17 years & $21 / 86 \mathrm{mg} / \mathrm{dl}$ & $\begin{array}{l}\text { Rich, educated, } \\
\text { affluent society, } \\
\text { high caste } \\
\text { brahmin }\end{array}$ & $\begin{array}{l}\text { Essential fatty acids } \\
\text { deprived diet for } \\
\sim 16 \text { years }\end{array}$ & $\begin{array}{l}\text { Hypotension, swaggering } \\
\text { gait, vomiting, sweating, } \\
\text { past surgery for widening } \\
\text { of foramina of skull base }\end{array}$ & $\begin{array}{c}\text { Foramen magnum constriction, } \\
\text { leading to cerebral, brainstem } \\
\text { edema, and she expired } \\
\text { bone metabolism ineffective. }\end{array}$ \\
\hline
\end{tabular}


reflecting on the poor consumption of fatty acids containing diet-specially they were using sunflower seed, refined oil, for many years-16 - 40 years; both patients were educated, rich, but the false concept of sunflower seed oil, refined oil, by its detrimental effect on cell anabolism, producing these degenerative diseases of dura mater, leading to empty sella status with hypopituitarism, and deranged metabolism, defaulted genomic repertoire of all tissues specially bone metabolism resulting in platybasia, having resulted in mortality.

Young girls who succumbed to platybasia, constricting foramen magnum, also was fed from childhood with love and concern with fatty acids deprived diet, [sunflower seed oil, refined oil, no fried preparations, no egg consumption, even dosa without oil].

Cholesterol is life moiety of cell, by being an important constituent of cell membrane, steroid hormones governing cell metabolism, safeguarding cell from neoplasm transformation and promote new cell formation, healing, and genomic repertoire.

Essential fatty acids deprived diet leads to impaired cholesterol synthesis, impaired cell metabolism, resulting in degenerative diseases of all [15] tissues $60 \%$, 6 fold increase, including empty sella syndrome, platybasia.

Hence the basic concept of cholesterol esters, derived from essential fatty acids consumed in the diet is the basic moiety of cell metabolism, new cell formation, steroid hormone synthesis, genomic repertoire, is to be reiterated. To address the prevailing fatty acids deprived diet and its deleterious effect on cell metabolism with a consequence of 6 fold, $60 \%$ increase in degenerative, neoplastic diseases. Consumption of virgin olive oil, virgin coconut oil, with fried preparations made of nuts and seeds [containing a seedling to sprout], is to be encouraged by medical curriculum. Contraception, abortion-non evidence based medical practice targets to prevent terminate life needs to be nullified from the medical curriculum.

\section{Conflicts of Interest}

The authors declare no conflicts of interest regarding the publication of this paper.

\section{References}

[1] Brown, M.S. and Goldstein, J.L. (1985) Exogenous Pathway, Endogenous Pathway. In: Goodman and Gilman's. The Pharmacological Basis of Therapeutics, 7th Edition, Macmillan, London, 827-828.

[2] Adams, R.D. and Victor, M. (1986) Intracranial Neoplasms, Principles of Neurology. 3rd Edition, Chapter 30, McGraw-Hill, New York, 500.

[3] Strachan, M.W.J. and Walker, B.R. (2010) Endocrine Disease, the Adrenal Glands. In: Davidson's Principles and Practice of Medicine, 21st Edition, Churchill Livingstone, Edinburgh, 774-775.

[4] Strachan, M.W.J. and Walker, B.R. (2010) Hypopituitarism, Davidson's Principles and Practice of Medicine. 21st Edition, Churchill Livingstone, Edinburgh, 785-787.

[5] Singh, V. (2015) Osteology of the Head and Neck. In: Textbook of Anatomy Head 
Neck and Brain, 2nd Edition, Volume 3, Elsevier, Amsterdam, 12-13.

[6] Inbar, O.C. (2016) Textbook of Focused NeuroSurgery. Jaypee Brothers, New Delhi, 335-337. https://doi.org/10.5005/jp/books/12911

[7] Bhargava, S.K. (2009) MusculoSkeletal System, Diagnostic Approach in Radiology. 10th Section, Peepee Publishers and Distributors, New Delhi, 516.

[8] Flavis, M.J. and Vokes, T.J. (2016) Pagets Disease and Other Dysplasia of Bone. In: Endocrinology and Metabolism, Harrison's Principles of Internal Medicine, Part 16, 19th Edition, Volume 3, McGraw-Hill, New York, 426e-2.

[9] Barrett, K.E., Barman, S.M., Boitano, S. and Brooks, H.L. (2012) Adrenal Cortex, Steroid Biosynthesis. In: Ganong's Review of Medical Physiology, 24th Edition, McGraw-Hill, New York, 360.

[10] Barrett, K.E., Barman, S.M., Boitano, S. and Brooks, H.L. (2012) Cholesterol Metabolism. In: Ganong's Review of Medical Physiology, 24th Edition, McGraw-Hill, New York, 30.

[11] Russel, R.M. and Suter, P.M. (2016) Vitamin and Trace Mineral Deficiency and Excess. In: Harrison's principles of Internal Medicine, Volume 3, 19th Edition, McGraw-Hill, New York, 96e-8.

[12] Elizabeth, J.S. (2015) Withered Tree' Concept Host, Achieved by Contraception, Abortion. Open Journal of Preventive Medicine, 5, 193.

[13] Mendelsohn, J. (1987) Principles of Neoplasia, Tumor Cell Biology. In: Harrison's Principles of Internal Medicine, 11th Edition, 2nd Volume, McGraw-Hill, New York, 422.

[14] Elizabeth, J.S. (2014) Increased Prevalence of Obesity and Fragmented Germ Cells. International Journal of Scientific and Research Publications, 4, 4.

[15] Brunton, L.L., Chabner, B.A. and Knollmann, B.C. (2011) Goodman and Gilman's: The Pharmacological Basis of Therapeutics. 12th Edition, McGraw-Hill, New York, 883-884. 